\title{
Procedimentos analíticos em perícia ambiental: gravimetria
}

O perito ambiental terá atenção às questões relativas à exatidão e à precisão esperada dos métodos dados e, além disso, não deve desprezar fatores como tempo e custo. O método mais exato para certa determinação pode ser muito demorado ou envolver o uso de reagentes caros. Por tal motivo, o apropriado é avaliar que exatidão se faz necessária. Em muitos casos, é possível escolher um método que, embora menos exato, proporcione, num tempo razoável, resultados satisfatórios.

Palavras-chave: Gravimetria; Perícia; Meio ambiente; Procedimentos.

\section{Analytical procedures in environmental expertise: gravimetry}

The environmental expert will pay attention to issues relating to the accuracy and precision expected of the methods given and, in addition, should not neglect factors such as time and cost. The most accurate method for certain determination can be very time-consuming or involve the use of expensive reagents. For this reason, it is appropriate to assess what accuracy is necessary. In many cases, it is possible to choose a method that, although less accurate, provides satisfactory results in a reasonable time.

Keywords: Gravimetry; Expertise; Environment; Procedures.

Topic: Química Agrícola e Ambiental

Reviewed anonymously in the process of blind peer
Received: 10/11/2020

Approved: 15/02/2021
Elenice Rachid da Silva Lenz (D)

Universidade Federal do Rio de Janeiro, Brasil

http://lattes.cnpq.br/4557023865361858

http://orcid.org/0000-0002-1440-4271

erachid@pet.coppe.ufri.br

Raphael do Couto Pereira

Universidade Federal Fluminense, Brasil

http://lattes.cnpq.br/2232319377341816

rcoutopereira1@gmail.com

Lais Alencar de Aguiar (D)

Universidade Federal do Rio de Janeiro, Brasil

http://lattes.cnpq.br/5785500333245448

http://orcid.org/0000-0002-1551-4085

aguiar.lais@gmail.com
Cleber Vinicius Vitorio da Silva (ID

Universidade Federal Rural do Rio de Janeiro, Brasil

http://lattes.cnpq.br/4275890458575782

http://orcid.org/0000-0001-8337-9615

clebervitorio88@gmail.com

Josimar Ribeiro de Almeida

Universidade do Estado do Rio de Janeiro, Brasil

http://lattes.cnpq.br/3215586187698472

http://orcid.org/0000-0001-5993-0665

almeida@poli.ufri.br
DOI: 10.6008/CBPC2237-9290.2021.001.0004
Referencing this:

LENZ, E. R. S.; PEREIRA, R. C.; AGUIAR, L. A.; SILVA, C. V. V.; ALMEIDA, J. R.. Procedimentos analíticos em perícia ambiental: gravimetria. Natural Resources, v.11, n.1, p.25-32, 2021. DOI:

http://doi.org/10.6008/CBPC2237-9290.2021.001.0004 


\section{INTRODUÇÃO}

Uma das decisões principais a ser tomada pelo Perito Ambiental, é a da escolha do procedimento mais eficiente de uma dada análise; para chegar à decisão correta, o Perito Ambiental deve ter familiaridade com os detalhes práticos das diversa técnicas e com os princípios teóricos sobre os quais se baseiam. Dispondo-se de uma amostra apropriada, é necessário que o Perito Ambiental dedique atenção à técnica, ou às técnicas mais convenientes de serem empregadas para as determinações requeridas. O Perito Ambiental deve ter o conhecimento das condições em que cada método é confiável e a consciência das interferências possíveis que podem ocorrer, e ser capaz de imaginar caminhos para evitar estes problemas (ALMEIDA et al., 2019). O Perito Ambiental terá atenção às questões relativas à exatidão e à precisão esperada dos métodos dados e, além disso, não deve desprezar fatores como tempo e custo (ALMEIDA et al., 2019). O método mais exato para certa determinação pode ser muito demorado ou envolver o uso de reagentes caros. Por tal motivo, o apropriado é avaliar que exatidão se faz necessária. Em muitos casos, é possível escolher um método que, embora menos exato, proporcione, num tempo razoável, resultados satisfatórios.

\section{RELATO}

Apesar das vantagens diversificadas dos métodos instrumentais, a sua generalizada adoção não tornou obsoletos os métodos clássicos; três fatores principais influenciam a situação (ALMEIDA et al., 2019):

A aparelhagem necessária para os procedimentos clássicos custo econômico justo e encontra se com facilidade em todos os laboratórios; no entanto, alguns instrumentos/aparelhos são Instrumentação típicos de Ciência Forense tem elevado custo (TANCREDI et al., 2013). De forma que sua adoção só se justifica quando são muitas as amostras a analisar, ou quando se trata da determinação de substâncias em quantidades diminutas (análise de traços, subtrações ou ultratraços). Nos métodos instrumentais é necessário efetuar uma operação de calibração, em que se usa amostra do material com a composição conhecida como a substância de referência (SOUZA et al., 2011). Enquanto um método instrumental é o ideal para a execução de um grande número de determinações de rotina, no caso de uma análise episódica, fora da rotina, é muitas vezes mais simples usar um método clássico do que ter o trabalho de preparar os padrões indispensáveis e calibrar o instrumento. Importante destacar que as pesquisas orientadas pelo método dialético revelam a historicidade do fenômeno e suas relações, em nível mais amplo, situam o problema dentro de um contexto complexo, ao mesmo tempo, estabelece e aponta as contradições possíveis dentre os fenômenos investigados. A investigação qualitativa é alicerçada na inseparabilidade dos fenômenos e seu contexto, pois, as opiniões, percepções e significados serão compreendidos com maior profundidade a partir da contextualização. A validade seria referente à semelhança entre o conceito e suas medidas, ao grau em que uma medida representa precisamente o que se espera. A garantia da validade começaria com a compreensão direta do que deve ser medido, sendo, portanto, uma questão de formulação da pesquisa. O método proposto foi dividido em três fases, as quais foram subdivididas em etapas para a realização do levantamento bibliográfico. Na primeira fase da pesquisa (Perguntas de pesquisa) verifica-se as principais decisões e 
definições acerca da pesquisa. As perguntas de pesquisa, ficam em destaque e servem como impulsos para o início da revisão. Define-se o tema para realizar o levantamento bibliográfico e o período disponível. Outras decisões são tomadas simultaneamente. Tais como a definição das palavras-chave, para atuarem como identificadores. Paralelamente, resumem os principais assuntos sobre o tema a se pesquisar; assim como as combinações das palavras-chave. Essas, por sua vez, podem ser feitas por meio da utilização dos operadores booleanos e em diferentes bases de dados tais como Portal de Periódicos CAPES, Base de dados SCIELO, Publish or Perish, EBSCO, entre outras. No presente caso, as bases de dados foram Web of Science (ou ISI), Plataforma SUSTENERE, Scielo e Scopus. Essas bases possuem fácil acesso, permitindo, por meio de suas ferramentas, uma pesquisa criteriosa seja realizada, abrangendo uma vasta quantidade de periódicos. A segunda fase (Seleção dos artigos) inicia o levantamento e a seleção dos artigos, utilizando-se dos critérios de exclusão. Utiliza-se das palavras-chave de exclusão para realizar classificação mais criteriosa dos artigos. Delimitando também o período. Na etapa seguinte ocorre o primeiro filtro dos artigos, faz-se uma seleção a partir dos títulos, identificando os não alinhados. Na próxima etapa se faz a leitura dos resumos para excluir os impertinentes ao tema pesquisado. A etapa seguinte contém uma análise subjetiva do pesquisador para identificar, nos artigos alinhados ao tema, aqueles que possuem maior relevância acadêmica. Uma análise bibliométrica indica a relevância do autor/artigo para a composição do referencial bibliográfico. A Fase 3 corresponde a Classificação dos artigos selecionados. Procede-se a organização das amostras de artigos selecionados. O objetivo é ordenar, um padrão que vai variar de acordo com a necessidade do pesquisador e a prioriza como foco para desenvolvimento temático. Evidencia-se a importância da análise minuciosa dos artigos que compõem a amostra. Em pesquisas qualitativas, a concepção de validade assume formas distintas, pois a discussão sobre escalas de medição não se aplica a métodos qualitativos, sendo necessária a compreensão da validade em outra perspectiva. Um atributo que se relaciona com a objetividade, com a possibilidade de repetição do experimento, com o fato de a pesquisa estar aberta à verificação por outras pessoas e com a capacidade de generalização (ALMEIDA et al., 2019). A validade pode ser vista genericamente como a correspondência entre a pesquisa e a realidade. Ela se refere à verificação dos resultados como verdadeiros e confiáveis. Ela estaria relacionada ao fato de os resultados refletirem com precisão a situação analisada e serem confiáveis, no sentido de que não haveria razões para deles duvidar; ou seja, a pesquisa é válida se as evidências fornecem o apoio necessário às suas conclusões (SOUZA et al., 2011). A intenção não é generalizar, mas sim descrever, analisar, buscar compreender.

\section{DISCUSSÃO}

\section{Análise de dados}

A análise gravimétrica, ou análise quantitativa ponderal, é o processo de isolar e de pesar um elemento, ou um composto definido de um elemento, na forma mais pura possível. O elemento, ou o composto, é separado de uma amostra pesada da substância sujeita à análise. Uma grande parte das determinações na análise gravimétrica refere-se à transformação do elemento, ou do radical a ser 
determinado, um composto estável e puro, que possa ser convertido, com facilidade, numa forma apropriada para a pesagem. $O$ peso do elemento, ou do radical, pode então ser calculado facilmente a partir do conhecimento da fórmula do composto e das massas atômicas relativas dos elementos constituintes. A separação do elemento, ou do composto que o contém, pode ser efetuada de diversas maneiras, e as mais importantes dentre elas são: (a) métodos de precipitação; (b) métodos de volatilização ou de evolução; (c) métodos eletroanalíticos; e (d) métodos de extração e cromatográficos. É conveniente mencionar, neste estágio, as razões de se continuar a adotar a análise gravimétrica apesar da desvantagem de ser, em geral, muito demorada. As vantagens oferecidas pela análise gravimétrica são: (a) É exata e precisa quando se usam as balanças analíticas modernas; (b) É fácil controlar as possíveis fontes de erro, pois os filtrados podem ser ensaiados para verificar se a precipitação foi completa, e os precipitados podem ser examinados em busca da presença de impurezas; (c) Tem a importante vantagem de ser um método absoluto, isto é, um método que envolve a medição direta sem a necessidade de qualquer forma de calibração; (d) As determinações podem ser feitas com aparelhos relativamente baratos, sendo um forno de mufla e, em casos mais dispendiosos, os cadinhos de platina. Duas aplicações gerais da análise gravimétrica são: (a) A análise de padrões a serem usados na verificação ou na calibração de técnicas instrumentais, ou em ambas; (b) As análises que exigem elevada exatidão, embora a natureza demorada.

Os métodos de precipitação são talvez os mais importantes de que trata a análise gravimétrica. 0 constituinte a ser determinado é precipitado da solução numa forma que seja tão pouco solúvel que não haja perda apreciável quando o precipitado for separado por filtração e pesado. Os seguintes fatores determinam o êxito de uma análise por precipitação. 1. O precipitado deve ser tão insolúvel que não haja perdas apreciáveis quando for recolhido por filtração. Na prática isto significa, usualmente, que a quantidade que permanece em solução não excede ao mínimo perceptível pela balança analítica comum, ou seja, 0,1mg; 2 . A natureza física do precipitado deve ser tal que possa ser separado da solução por filtração e possa ser lavado até estar isento de impurezas solúveis. Estas condições exigem que as partículas tenham um tal tamanho que não passem através do meio filtrante e que as dimensões das partículas não sejam afetadas (pelo menos não sejam diminuídas) pelo processo de lavagem; 3 . O precipitado tem que ser conversível a uma substância pura de composição química definida; consegue-se está conversão ou por calcinação ou por uma operação química simples, como a evaporação num solvente apropriado. 0 fator 1 depende da inteireza da precipitação, como já se analisou no estudo do princípio do produto de solubilidade e da influência, sobre a solubilidade de um precipitado, de um sal com um íon comum, de sais sem íon comum, e ácidos e de bases e da temperatura. Admitiu-se, ao longo do estudo, que o composto separado da solução era quimicamente puro; este não é, porém, sempre o caso. A pureza do precipitado depende, entre outras coisas, das substâncias presentes na solução antes e também depois da adição do reagente e das condições experimentais exatas da precipitação. A fim de entender a influência destes e de outros fatores, será necessário apresentar um relato resumido das propriedades dos coloides. Os problemas que aparecem com alguns precipitados incluem a coagulação, ou floculação, de uma dispersão coloidal de sólido finamente dividido, a fim de possibilitar a filtração e impedir a repeptização na lavagem do precipitado. As precipitações se fazem, usualmente em bécheres de vidro 
resistente, e a solução do precipitante é adicionada lentamente (por exemplo, mediante uma pipeta, uma bureta ou um funil com torneira), agitando-se eficientemente a solução com a diluição conveniente. A adição deve sempre ser feita sem projeção, o que se consegue deixando a solução do reagente escorrer pela parede do bécher ou do vaso de precipitação. Em geral basta um excesso moderado de reagente; um excesso muito grande pode levar ao aumento da solubilidade ou à contaminação do precipitado. Depois de o precipitado decantar, deve-se sempre adicionar algumas gotas do precipitante para verificar a ocorrência de precipitação extra. Como regra geral, não se filtra os precipitados imediatamente depois de terem sido formados. A maioria dos precipitados, exceto os definitivamente coloidais - como o hidróxido de ferro - precisa de maior ou menor digestão a fim de completar-se a precipitação e de todas as partículas atingirem tamanho suscetível de filtração. Em alguns casos a digestão se faz deixando-se o bécher descansar, com o precipitado em contato com a água-mãe, na temperatura ambiente, durante 12 a 24 horas; em outro, casos, quando se pode elevar a temperatura, a digestão se faz nas vizinhanças da temperatura de ebulição da solução. Para o aquecimento, usam-se placas de aquecimento, banhos de água ou até uma chama baixa, evitando as projeções do líquido; em todos os casos, o bécher deve estar coberto por um vidre de relógio com a face convexa para baixo. Quando a solubilidade do precipitado for apreciável, pode ser indispensável deixar a solução atingir a temperatura ambiente antes da filtração.

A filtração é a separação do precipitado da água-mãe com o objetivo de conseguir-se o precipitado e o meio filtrante quantitativamente livres da solução. Os meios adotados para a filtração são: (1) papel de filtro; (2) placas de frita porosa de vidro resistente, como por exemplo, Pyrex (cadinhos filtrantes de vidro sinterizado), de sílica (cadinhos filtrantes de Vitreosil) ou de porcelana (cadinhos filtrantes de porcelana). A escolha de um meio filtrante será controlada pela natureza do precipitado (o papel de filtro é especialmente apropriado para precipitados gelatinosos) e também pela questão do custo. As limitações dos diversos meios filtrantes estão expostas nas considerações seguintes.

A maior parte dos precipitados é obtida na presença de um ou mais de um composto solúvel. Em virtude de estes compostos não serem, em muitos casos, voláteis na temperatura em que o precipitado sofre a secagem final, é preciso lavar o precipitado a fim de remover o material estranho tão completamente quanto possível. O volume de líquido de lavagem, necessário para remover o material estranho, deve ser o menor possível, pois nenhum precipitado é absolutamente insolúvel. Devem-se fazer ensaios qualitativos para verificar a remoção de impurezas, usando pequenos volumes da solução de lavagem filtrada. Além disso, é mais eficaz lavar com diversas parcelas de líquido de lavagem, esgotando o líquido completamente entre cada duas lavagens, do que lavar com uma ou duas parcelas volumosas do líquido, ou do que adicionar o líquido de lavagem enquanto ainda houver solução no filtro.

O líquido de lavagem ideal deve atender, tanto quanto possível, às seguintes condições: 1 . Não ter ação solvente sobre o precipitado, mas dissolver com facilidade as substâncias estranhas; 2 . Não ter ação dispersora sobre o precipitado; 3 . Não formar produto volátil ou insolúvel com o precipitado; 4 . Ser facilmente volatilizado na temperatura de secagem do precipitado; 5. Não conter substância que tenha a possibilidade de interferir com as determinações subsequentes no filtrado. Na maioria dos casos especialmente se o 
precipitado decantar com rapidez ou for gelatinoso, pode-se fazer lavagem por decantação. Em todos os casos é necessário fazer um ensaio para verificar se a lavagem foi completa; para isto, coleta-se uma pequena amostra da solução de lavagem, depois que se estima ter sido removida a maior parte das impurezas, e efetua-se o ensaio qualitativo apropriado. Quando a filtração for feita sob sucção, coloca-se um pequeno tubo de ensaio sob o funil que suporta o cadinho filtrante.

Depois de um precipitado ter sido filtrado e lavado, este deve ser levado a composição constante antes de ser pesado. $O$ tratamento a ser adotado depende da natureza do precipitado e também da natureza do meio filtrante; este tratamento consiste na secagem ou calcinação do precipitado. O termo a ser empregado depende da temperatura em que o precipitado for aquecido. Não há, no entanto, uma temperatura definida abaixo da qual ou acima da qual, o precipitado será seco ou calcinado. O significado será apropriadamente explicitado, para os nossos objetivos, se designarmos como secagem a operação efetuada baixo de $250^{\circ} \mathrm{C}$ (temperatura máxima que se atinge com facilidade nas estufas usuais de secagem, elétricas e com controle termostático) e como calcinação a operação efetuada acima de $250^{\circ} \mathrm{C}$ até $1200^{\circ} \mathrm{C}$. Os precipitados que sofrerão secagem deverão ser coletados em papel de filtro ou em cadinhos filtrantes de vidro sinterizado ou de porcelana. Os precipitados que sofrerão calcinação deverão ser coletados em papel de filtro, em cadinhos filtrantes de porcelana ou em cadinhos filtrantes de sílica. A calcinação se faz colocando-se o cadinho numa cápsula especial de ignição e aquecendo-se com um combustor apropriado; ou então, o cadinho (e na realidade qualquer tipo de cadinho) pode ser colocado num forno de mufa com calefação elétrica, equipado com um pirômetro e dispositivo de controle da temperatura. É necessário levar em conta a informação proporcionada pela análise termogravimétrica no que se refere ao intervalo de temperatura em que o precipitado pode ser aquecido para ter uma composição determinada. A curva termogravimétrica, em alguns casos, é influenciada pelas condições experimentais da precipitação e que mesmo quando a curva obtida não for horizontal será possível ter uma pesagem apropriada num certo intervalo de temperatura. Apesar disto, os termogramas proporcionam dados valiosos sobre o intervalo de temperatura dentro do qual um precipitado tem uma composição constante, nas condições em que a análise termogravimétrica tiver sido feita; estes dados proporcionam, no mínimo, um guia para a temperatura em que um precipitado deve ser seco e aquecido com objetivos quantitativos, mas deve-se dispensar a devida atenção às propriedades químicas gerais da fôrma que estiver sendo pesada. Embora os precipitados que exijam calcinações sejam usualmente recolhidos em cadinhos filtrantes de porcelana ou de sílica, existem ocasiões em que se usa papel de filtro e, por isso, é necessário descrever o método a ser adotado nestes casos. A técnica exata dependerá de o precipitado poder ou não ser calcinado com segurança em contato com o papel de filtro. Deve-se recordar que alguns precipitados, como o sulfato de bário podem ser reduzidos ou modificados, em contato com o papel de filtro ou com seus produtos de decomposição.

Os métodos de volatilização, ou de desprendimento, dependem, essencialmente, da remoção de constituintes voláteis. Isto se pode conseguir de diferentes formas: (1) pela calcinação ao ar ou em corrente de gás inerte; (2) pelo tratamento com um reagente químico que torna volátil o constituinte que se deseja; e (3) pelo tratamento com um reagente químico que torna involátil o constituinte que se deseja. A substância 
volatilizada pode ser absorvida numa quantidade pesada de um meio apropriado, quando a determinação for uma determinação direta, ou então se determina o peso de resíduo remanescente da volatilização de um componente e calcula-se a proporção do constituinte a partir da perda de peso; este método é um método indireto. A determinação da umidade ligada superficialmente, ou da água de cristalização de compostos hidratados, por exemplo, pode ser feita simplesmente pelo aquecimento da substância até uma temperatura conveniente e pesagem do resíduo. As substâncias que se decompõem no aquecimento podem ser estudadas com maior profundidade mediante a análise térmica.

$\mathrm{Na}$ análise eletrogravimétrica, o elemento a ser determinado é eletroliticamente depositado sobre um eletrodo conveniente. Não é necessária a filtração e, desde que as condições experimentais sejam cuidadosamente controladas, evita-se frequentemente a codeposição de dois metais. Embora este procedimento tenha sido superado, em grande extensão, pelos métodos potenciométricos baseados no uso de eletrodos seletivos a íons, é um método que tem muitas vantagens, quando for aplicável. A eletrodeposição é governada pela Lei de Ohm e pelas duas Leis de Faraday sobre a eletrólise. Estas duas leis afirmam: 'As quantidades de substâncias libertadas (ou dissolvidas) nos eletrodos de uma célula eletrolítica são diretamente proporcionais à quantidade de eletricidade que passa pela solução. As quantidades de diferentes substâncias, libertadas ou dissolvidas por uma mesma quantidade de eletricidade, são proporcionais às respectivas massas atômicas (ou molares) relativas divididas pelo número de elétrons envolvidos no respectivo processo eletródico'.

\section{CONSIDERAÇÕES FINAIS}

Conclui-se, pela segunda lei, que quando uma dada corrente passa, em série, através de soluções contendo sulfato de cobre e nitrato de prata, os pesos de cobre e de prata, depositados num certo intervalo de tempo, estarão entre si na razão de 63,55/2 para 107,87/1. A Lei de Ohm exprime a relação entre três grandezas fundamentais, a corrente, a força eletromotriz e a resistência: A corrente I é diretamente proporcional à força eletromotriz $E$ e indiretamente proporcional à resistência $R$, ou seja: I = E/R. Com exceção do chumbo, que a partir de soluções de ácido nítrico deposita-se no anodo como $\mathrm{PbO2}$, os íons são depositados no catodo, na forma metálica.

\section{REFERÊNCIAS}

ALMEIDA, J. R.; SILVA, C. E.; SILVA, C. V. V.; AGUIAR, L. A.; GARCIA, V. S.; SOUZA, C. P.; LENZ, E. R. S.; LINS, G. A.; ALMEIDA, S. M.. Multifatorialidade em saúde ambiental. Environmental Scientiae, v.1, p.26-47, 2019. DOI: https://doi.org/10.6008/CBPC2674-6492.2019.002.0002

ALMEIDA, J. R.; SILVA, C. E.; SILVA, C. V. V.; AGUIAR, L. A. GARCIA, V. S.; SOUZA, C. P.; LENZ, E. R. S.; LINS, G. A.; ALMEIDA, S. M.. Política e economia de vigilância em saúde ambiental. Environmental Scientiae, v.1, p.1-25, 2019. DOI: https://doi.org/10.6008/CBPC2674-6492.2019.002.0001

TANCREDI, N. S. H.; ALMEIDA, J. R.; LINS, G. A.; GUERRA, A. J. T.; JORGE, M. C. O.. Uso de geotecnologias em laudos periciais ambientais: estudo de caso no município de Jacundá, Pará. Revista Geografar, v.7, p.9-12, 2012. DOI: http://dx.doi.org/10.5380/geografar.v7i1.21252

SOUZA, F. M. N.; SILVA, C. E.; AGUIAR, L. A.; ALMEIDA, J. R.. Proposta para utilização da simulação computacional em análise de risco, avaliação de desempenho e sistemas de gestão ambiental. Revista Ibero-Americana de Ciências Ambientais, v.2, p.39-63, 2011. DOI: http://doi.org/10.6008/ESS2179-6858.2011.002.0003

SOUZA, F. M. N.; SILVA, C. E.; AGUIAR, L. A.; ALMEIDA, J. R. Proposta para utilização da simulação computacional em análise de risco, avaliação de desempenho e sistemas de 
gestão ambiental. Revista Ibero-Americana de Ciências

Ambientais, v.2, p.39-63, 2011. DOI:

A CBPC - Companhia Brasileira de Produção Científica (CNPJ: 11.221.422/0001-03) detém os direitos materiais desta publicação. Os direitos referem-se à publicação do trabalho em qualquer parte do mundo, incluindo os direitos às renovações, expansões e disseminações da contribuição, bem como outros direitos subsidiários. Todos os trabalhos publicados eletronicamente poderão posteriormente ser publicados em coletâneas impressas sob coordenação da Sustenere Publishing, da Companhia Brasileira de Produção Científica e seus parceiros autorizados. Os (as) autores (as) preservam os direitos autorais, mas não têm permissão para a publicação da contribuição em outro meio, impresso ou digital, em português ou em tradução. 